\title{
Insertion of Dual Drugs of Hypertension in Gelatin Pockets for Chrono pharmacotherapy and its Evaluation by in-vitro and ex- vivo Studies
}

\author{
Madhuri Desavathu*, Pathuri Raghuveer, Pallikonda Sarada \\ Department of Pharmaceutics, University College of Pharmaceutical Sciences, Acharya Nagarjuna University, Guntur-522510, \\ Andhra Pradesh, INDIA.
}

\begin{abstract}
Objective: The project was aimed to fabricate and evaluate a pulsatile capsule to program the release of dual antihypertensive drugs to mimic the circadian pattern of Blood Pressure. The formulation was optimized to repeatedly release the drug in pulses during the vulnerable period of 4 a.m. to noon upon administration during bed time. Methods: Formulation was prepared by means of Pulsincap technology. It consisted of an insoluble capsule body housing a layer of swellable polymer, a Losartan tablet sealed by an erodible polymer tablet. The system was capsulated in non-biodegradable body capped with water soluble cap containing fast releasing Amlodipine-sorbitol granules. The developed formulation was studied for physical characteristics, lag time determination, in vitro and ex vivo release. Results: The capsule cap dissolved in acidic $\mathrm{pH}$ released $99.29 \%$ of the amlodipine within $3 \mathrm{~h}$. The swellable polymer layer at the base of capsule pushed the plug along with losartan tablet out after a lag time of $6-7 \mathrm{~h}$ with $85.93 \%$ drug being released at the end of $12 \mathrm{~h}$ providing a time controlled need based release. Pulsincap formulated with Amlodipine-Sorbitol granules of G3 formulation, Losartan core tablet of C4 formulation and Erodible tablet of Guar gum with E4 formulation showed highest drug release over the period of $12 \mathrm{~h}$ and release was found to be followed Higuchi model kinetics. The present research study results have confirmed that the modified pulsincap of dual drugs is a suitable device for the time dependent and site specific delivery. Conclusion: This approach can be useful for the timed release of a combination antihypertensive medication and may provide effective $24 \mathrm{~h}$ control of Blood Pressure in hypertensive patients. The formulation was successfully designed to achieve enhanced bioavailability and dual pulsatile release. Bedtime dosing will more efficiently control the circadian spikes of hypertension in the morning.
\end{abstract}

Key words: Pulsatile capsule, Erodible polymer tablet, Hypertension, Swellable polymer, Losartan Potassium, Amlodipine besylate.

\section{INTRODUCTION}

Recent studies show that most body functions display circadian rhythms, which are endogenous oscillations, and self-sustaining that occur with a periodicity of about $24 \mathrm{~h}$ and are synchronized based on internal biological clocks related to the sleep-wake cycle. The best-known circadian rhythms include body temperature, heart rate, blood pressure, blood flow, and gastric pH. Moreover, in a number of organs, their functions vary with the time of the day and it is increasingly recognized that there are rhythmic and temporal patterns in the manifestation of many disease states. ${ }^{1-2}$ Angina pectoris and hypertension are typical examples of diseases which follow a circadian rhythm. ${ }^{3-7}$ In persons with normal BP and uncomplicated essential hypertension, BP declines to lowest levels during night time sleep, rises abruptly with morning awakening, and attains near peak or peak values during the first hours of diurnal activity. So, the importance of the
Submission Date: 06-10-2017; Revision Date: 17-05-2018; Accepted Date: 14-08-2018

DOI: 10.5530/ijper.52.4s.97 Correspondence: Mrs. Madhuri Desavathu, Assistant Professor, Department of

Pharmaceutics, University College of Pharmaceutical Sciences, Acharya Nagarjuna University, Guntur-522510, Andhra Pradesh, INDIA. Phone: +918985133852 E-mail: madhuridesavathu@ gmail.com

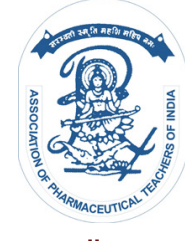

www.ijper.org 
time of administration of antihypertensive drugs is impeccable ${ }^{8-10}$ for ordinary preparations with immediate-release, patients with hypertension need to take their medicine in the early morning, which can cause non-compliance. ${ }^{11-12}$ Although sustained-release dosage forms have been developed to produce effective blood drug concentrations that are maintained for a longer time to prevent angina pectoris and to treat hypertension, too long a treatment time can result in a lot of side effects. ${ }^{13-14}$ For these reasons, drug delivery and therapy should be modified to achieve an effective drug level only at the required time. Chronotherapeutics is defined as the purposeful delivery of medications at time when it is most needed i.e. to match circadian rhythm of the disease. ${ }^{15-16}$ This can be achieved by using a pulsatile drug delivery system for the therapy involved. The reason behind a pulsatile drug delivery system is that the administration of a drug formulated in such a delivery system, i.e., taken at bedtime with a programmed start of drug release in the early morning hours, which could offer a more effective therapy Pulsatile drug release is the expeditious delivery of drug after a predetermined lag time. Several dissolving, erodible and rupturable systems have been studied for formulating pulsatile drug delivery systems. Out of which dissolving and swellable systems have some potential problems of either premature release (for highly soluble drugs) or retarding the release of drug after a lag time. ${ }^{17}$ To eradicate the abovementioned problems, we aimed to develop chronomodulated rupturable that can be administered at bedtime which would rapidly release drug after a lag time of $6 \mathrm{~h}$. Than atypical controlled-release drug delivery system could, provided that the most suitable drugs is chosen. ${ }^{18}$ Drug selected for this study are losartan potassium and amlodipine. In order to achieve predetermined lag time and in vitro drug release profile the weight (thickness) and composition (lactose/guar gum ratio) of erodible tablet was optimized, resulting in better therapeutic effect and hence better patient compliance could be achieved. The present research work was aimed to formulate and evaluate the Pulsatile drug delivery systems of both drugs prepared using different ratios of polymers. In vitro study is carried out for both drugs Amlodipine and losartan potassium formulation and selected formulation(s) in vitro study is compared with pulsatile capsules. Previously, Nayak et al. developed a pulsatile capsule dosage form of valsartan, which can provide timed release of valsartan and may be helpful for patients suffering from morning surge. Similarly, Li et al. and Zhou et al. successfully developed a novel two-step release system by combining an effervescent osmotic pump tablet and pulsed-release tablet into one hard capsule, which exhibited drug-release that is in accordance with the circadian rhythms of cardiovascular disease. These pulsatile capsule designs have inspired us to re-design and formulate a programmed, dual drug loaded pulsatile release capsule for hypertension, which could mimic the circadian rhythm of BP and counteract its early morning rise, without causing a precipitous decline at night

\section{MATERIALS AND METHODS}

\section{Materials}

Losartan Potassium and Amlodipine Besylate as an endowment sample from Hetero Laboratories Ltd., Hyderabad. Guar gum and Xanthum gum were obtained from Thermo fisher scientific India Pvt Ltd., Mumbai. Avicel PH 101, PVP K30 were obtained from Merck specialities Pvt Ltd. Crosscarmellose sodium was obtained from National Scientific Products, Vijayawada. All other materials used were of analytical grade and were produced commercially.

\section{Methods}

\section{Preparation of pulsatile capsules}

The Pulsatile capsules were prepared by assembling Amlodipine granules, Erodible tablet, Losartan core tablet and swelling polymer into a water insoluble capsule body. The preparation was given below:

\section{Preparation of Amlodipine granules}

Granules were prepared with sorbitol by melt granulation technique. Required amount of Sorbitol was melted in a china dish to which Amlodipine was added, stirred rapidly, cooled and passed through \#22 sieve to obtain granules in 1:1(G1), 1:0.5(G2), 1:0.25(G3).

\section{Preparation of Losartan core tablets}

Using the selected super disintegrant, tablets of Losartan potassium (C1-C4) were prepared employing different excipients stated in Table 1 . The powder containing drug and (losartan potassium), disintegrant (Avicel PH101) / Super disintegrants (crosscarmellose sodium) and PVP K30 was homogeneously mixed followed by addition of lubricant (magnesium stearate) and glidant (talc). The tablets were made by direct compression using single punch tablet machine electrically operated tablet punching machine

\section{Preparation of water insoluble capsule body}

The bodies and caps of gelatin capsules were separated manually. By the means of crosslinking of gelatin capsules with formaldehyde, insoluble capsule bodies were made. ${ }^{19-20} 25 \mathrm{ml}$ of $37 \% \mathrm{w} / \mathrm{v}$ formaldehyde and small 


\begin{tabular}{|c|c|c|c|c|}
\hline Table 1: Formulation chart of Losartan core tablets. \\
\hline \multirow{2}{*}{ Ingredient } & \multicolumn{5}{|c|}{ Quantity taken (mg) } \\
\cline { 2 - 5 } & $\mathbf{C 1}$ & $\mathbf{C 2}$ & $\mathbf{C 3}$ & $\mathbf{C 4}$ \\
\hline Losartan potassium & 50 & 50 & 50 & 50 \\
\hline Avicel PH101 & 42 & 40 & 38 & 36 \\
\hline PVP K30 & 4 & 4 & 4 & 4 \\
\hline Crosscarmellose sodium & - & 2 & 4 & 6 \\
\hline Magnesium stearate & 2 & 2 & 2 & 2 \\
\hline Talc & 2 & 2 & 2 & 2 \\
\hline Total weight of tablet $(\mathbf{m g})$ & 100 & 100 & 100 & 100 \\
\hline
\end{tabular}

\begin{tabular}{|c|c|c|c|c|}
\hline \multirow{2}{*}{ Table 2: Formulation chart of Erodible tablets. } \\
\cline { 2 - 5 } Ingredient & \multicolumn{5}{|c|}{ Quantity taken (mg) } \\
\cline { 2 - 5 } & E1 & E2 & E3 & E4 \\
\hline Lactose & 46 & 21 & 69 & 31.5 \\
\hline Xanthum gum/Guar gum & 50 & 75 & 75 & 112.5 \\
\hline Magnesium stearate & 2 & 2 & 3 & 3 \\
\hline Talc & 2 & 2 & 3 & 3 \\
\hline Total weight of tablet (mg) & 100 & 100 & 150 & 150 \\
\hline
\end{tabular}

amount of potassium permanganate was taken into a desiccator to generate formalin vapours. Then the capsule bodies placed in a wire mesh board were exposed to fumes for $6 \mathrm{~h}$, and then dried at $40^{\circ} \mathrm{C}$ for 12 $\mathrm{h}$ in order to evaporate the solvent and dried at room temperature. Finally, the insoluble capsule bodies were formed.

\section{Preparation of Erodible tablets}

The composition of the tablets is given in Table 2 . All materials were passed through sieve no. 60. Direct compression erodible tablet formulations containing guar gum (GG)) were prepared by weighing gum and adding directly compressible lactose. Magnesium stearate and talc were added to each blend and further mixed. The resultant blends were tableted to $100 \mathrm{mg}$ and $150 \mathrm{mg}$ using $6.5 \mathrm{~mm}$ die cavities using Riddhi mini tablet press punching machine.

\section{Characterization and Evaluation}

The following characterization and evaluations were carried out in triplicate $(\mathrm{n}=3)$.

\section{Compatibility studies}

Fourier transform infrared (F'T-IR) spectrometry was carried out to study the compatibility between drug and polymers used. The Fourier transform infrared (FT-IR) spectrum was obtained by the $\mathrm{KBr}$ pressed pellet technique using a Shimadzu, FT-IR 8400S.

\section{Evaluation of Amlodipine granules Micromeritic properties}

The angle of repose of Amlodipine and formulation mixture was determined by the fixed funnel method. ${ }^{21}$ The loose bulk density (LBD) and tapped bulk densities (TBD) were determined by using a density apparatus (Serwell Instruments, Bangalore, India). The Carr's index $(\%)$ and the Hausner ratio were calculated. ${ }^{22}$

\section{Drug content}

The drug content of the AMLO granules was estimated using a UV-visible spectrophotometer, Shimadzu-1800. An accurately weighed quantity of granules (equivalent to $10 \mathrm{mg}$ of AMLO) was taken and dissolved in $\mathrm{pH} 1.2$ HCL buffer solution; from this $1 \mathrm{~mL}$ of solution was diluted to $10 \mathrm{~mL}$ and assayed for drug content at $296 \mathrm{~nm}$. The samples were altered prior to analysis.

\section{In vitro release studies of granules}

Drug release studies from formulations were carried out in triplicate using USP Type II (Labindia dissolution apparatus), $\mathrm{pH} 1.2 \mathrm{HCl}$ buffer as dissolution medium at $75 \mathrm{rpm}$ and $37^{\circ} \mathrm{C} \pm 0.5^{\circ} \mathrm{C}$ for $2.5 \mathrm{~h}$. An aliquot of samples was withdrawn periodically at every $30 \mathrm{~min}$ interval and the volume was replaced with an equivalent volume of plain dissolution medium. Samples were analysed spectrophotometrically at $296 \mathrm{~nm}$ after suitable dilution.

\section{Evaluation of Losartan core tablets \\ Pre-compression parameters}

The tablet blends were evaluated for their bulk density, tapped density, Carr's index and other flow properties.

\section{Post-compression parameters}

The post compression parameters such as tablet hardness, weight variation, friability, drug content and disintegration were studied.

\section{In vitro drug release studies of tablets}

Drug release studies from formulations were carried out in triplicate using USP Type II (Labindia dissolution apparatus), distilled water as dissolution medium at $75 \mathrm{rpm}$ and $37^{\circ} \mathrm{C} \pm 0.5^{\circ} \mathrm{C}$ for $5 \mathrm{~h}$. An aliquot of samples was withdrawn periodically at every $30 \mathrm{~min}$ interval and the volume was replaced with an equivalent volume of plain dissolution medium. Samples were analysed spectrophotometrically at $234 \mathrm{~nm}$ after suitable dilution.

\section{Test for formaldehyde treated empty capsule bodies}

Various physical tests, such as identification attributes, visual defects, dimension changes, solubility studies and 
Qualitative chemical test for free formaldehyde were carried out.

\section{Qualitative chemical test for free formaldehyde}

Formaldehyde solution $(0.002, \mathrm{w} / \mathrm{v})$ was used as a standard solution and a sample solution was prepared by cutting 25 formaldehyde-treated bodies into small pieces and taken into a beaker containing distilled water. This was then stirred for $1 \mathrm{~h}$ with a magnetic stirrer, to solubilize the free formaldehyde. The solution was then filtered into a $50 \mathrm{~mL}$ volumetric flask, washed with distilled water and volume was made up to $50 \mathrm{~mL}$ with the washings. To $1 \mathrm{~mL}$ of sample solution, $9 \mathrm{~mL}$ of water was added; $1 \mathrm{~mL}$ of the resulting solution was taken into a test tube and mixed with $4 \mathrm{~mL}$ of water and $5 \mathrm{~mL}$ of acetone. The test tube was warmed in a water bath at $40^{\circ} \mathrm{C}$ and allowed to stand for $40 \mathrm{~min}$. The solution was not more intensely coloured than a reference solution prepared at the same time and in the same manner using $1 \mathrm{~mL}$ of standard solution in place of the sample solution. The comparison should be made by examining tubes down their vertical axis. ${ }^{23}$

\section{Evaluation of Erodible tablet}

\section{Pre compression and post compression parameters}

The prepared erodible tablets were evaluated for pre and post compression parameters.

\section{Water uptake studies}

By initially exposing tablets to $\mathrm{pH} 1.2 \mathrm{HCl}$ buffer for $3 \mathrm{~h}$ followed by distilled water for the next $9 \mathrm{~h}$ with $37 \pm 0.5^{\circ} \mathrm{C}$ and $75 \mathrm{rpm}$ water uptake studies can be performed. At pre-determined time points, tablets were carefully blotted with tissue paper to remove the surface water and then weighed. ${ }^{24}$ Water uptake was calculated by using following equation

$$
\text { Water uptake }(\%)=\frac{\text { Wet weight }- \text { Dry weight }}{\text { Wet weight }} \times 100
$$

\section{Lag time determination and Drug release}

The lag time was determined by visual observation of the pulsatile capsules in a USP II paddle apparatus (medium: $0.1 \mathrm{~N} \mathrm{HCl}$ for $3 \mathrm{~h}$ followed by Distilled water for $9 \mathrm{~h} 37 \pm 0.5^{\circ} \mathrm{C}$, rotation speed $75 \mathrm{rpm}$ ) and was defined as the time point. ${ }^{25}$ The body was sealed with water soluble cap and drug release was observed in $\mathrm{HCl}$ buffer, $\mathrm{pH} 1.2$ for $2 \mathrm{~h}$ followed by distilled water for $10 \mathrm{~h}$ using USP apparatus II. Aliquot samples were withdrawn each hour for $12 \mathrm{~h}$, replaced with fresh media and analysed spectrophotometrically.

\section{In vitro release and kinetics}

of chronotherapeutically active pulsatile capsular drug delivery system

The release rates of the assembled capsules $(n=3)$ were determined using a USP II (Labindia dissolution apparatus) at a paddle speed of $75 \mathrm{rpm}$ in $500 \mathrm{ml}$ of a 0.1 $\mathrm{N} \mathrm{HCl}$ buffer solution $(\mathrm{pH} 1.2)$ at $37 \pm 0.5^{\circ} \mathrm{C}$ for $3 \mathrm{~h}$ followed by distilled water for $9 \mathrm{~h}$. The concentration of the drug from the dissolution test was automatically measured at 296 and $234 \mathrm{~nm}$ by UV/VIS spectrophotometer for every $30 \mathrm{~min}$. The dissolution data obtained were plotted as percent cumulative drug released versus time.

\section{Continuous dissolution-absorption study using everted intestine segment (Ex vivo studies)}

\section{Isolation of everted segment}

Male sheep's intestine was bought from the local market. The Krebs-Ringer solution was prepared by combining $6.3 \mathrm{~g} \mathrm{NaCl}, 0.35 \mathrm{~g} \mathrm{KCl}, 0.14 \mathrm{~g} \mathrm{CaCl}_{2}, 0.16 \mathrm{~g} \mathrm{KH}_{2} \mathrm{PO}_{4}$, $0.15 \mathrm{~g} \mathrm{MgSO}_{4} \cdot 7 \mathrm{H}_{2} \mathrm{O}, 2.1 \mathrm{~g} \mathrm{NaHCO}_{3}$ and $5 \mathrm{~g}$ glucose in one litre of distilled water. For isolation of everted intestine, the sheeps were slaughtered, a median incision of the abdomen was performed, and the small intestine was freed. The lumen was carefully cleared from mucus by rinsing with a $\mathrm{pH} 7.4$ buffer solution (Krebs-Ringer solution). An intestinal segment of the first $10 \mathrm{~cm}$ length was removed and transferred to oxygenated Krebs-Ringer solution. It was washed thoroughly with warm Krebs-Ringer solution. The proximal extremity of the intestine was turned back and ligated on a glass rod to form an everted bag.

\section{Design of Continuous Dissolution-Absorption System Using Everted Intestine Segment}

The in vitro continuous dissolution-absorption system consisted of USP dissolution Apparatus II and a side-byside perfusion apparatus holding isolated everted intestine segment. In this system, drug dissolution from the pulsatile capsule and permeation across everted intestine occurred simultaneously. The dissolution medium used was $1000 \mathrm{~mL}$ of $0.1 \mathrm{~N} \mathrm{HCL}$ for $3 \mathrm{~h}$ and the dosage form was removed and transferred to deareated water was maintained at $37 \pm 0.5^{\circ} \mathrm{C}$. The perfusion apparatus consisted of two glass tubes, $\mathrm{A}$ and $\mathrm{B}$, connected together. Tube B had a bent cannula at its lower end, and tube A, a straight cannula at its lower end. The distance between the two cannula was kept constant. The isolated everted intestinal segment was fixed between the ends of tubes A and B. The ends of the intestine were tied in position with a thread. The apparatus was immersed completely into the dissolution vessel. The 
samples were withdrawn from dissolution $(5 \mathrm{ml})$ as well as from cannula $(3 \mathrm{ml})$ at preselected time intervals and replaced with fresh media. ${ }^{26}$

\section{Procedure for Absorption Studies in the Continuous Dissolution-Absorption System}

In the proposed design of a continuous dissolutionabsorption system, sampling can be done simultaneously for measurement of the in vitro dissolution and absorption profiles of the drug. The dissolutionabsorption studies were performed in two parts. In the first part of study, a marketed, slow-release tablet of combination with Amlodipine and Losartan were used. The dissolution medium consisted of $1000 \mathrm{~mL}$ distilled water maintained at $37 \pm 0.5^{\circ} \mathrm{C}$. A fresh intestinal segment was clamped to the dissolution apparatus. The total volume of the absorption compartment (tube A and tube B) was $35 \mathrm{~mL}$ of Krebs-Ringer solution. The drug diffused from dissolution medium (mucosal side) to the serosal side (absorption compartment). The marketed, slow-release tablet (MRKT-I and MRKT-II) was transferred to the dissolution basket of the designed system. The tablet was rotated at $75 \mathrm{rpm}$ speed. Dissolution samples $(2 \mathrm{~mL})$ were withdrawn at preselected time interval up to $6 \mathrm{~h}$. The dissolution samples were taken with replacement at $0.5,1,2,3,4,5$ and $6 \mathrm{~h}$ and the released drugs was determined spectrophotometrically at 296 and $234 \mathrm{~nm}$ respectively. The transported drug from the absorption compartment was sampled with replacement (Krebs-Ringer solution) at 0.5, 1, 2, 3, 4, $5,6,7,8,9,10,11$ and $12 \mathrm{~h}$ and analysed spectrophotometrically. To allow time for drug to circulate from the dissolution vessel to the everted intestine surface, absorption samples were collected 3 min later than their corresponding dissolution samples. ${ }^{3}$ The whole experiment was repeated in triplicate $(\mathrm{n}=3)$ using fresh dissolution medium as well as fresh intestinal segment each time. The second part of the study was performed using the dissolution medium as $1000 \mathrm{~mL}$ of distilled water maintained at $37 \pm 0.5^{\circ} \mathrm{C}$. The paddle rotation speed was $75 \mathrm{rpm}$. Similarly, fresh intestinal segment was used for each concentration for the absorption study. The dissolved drug diffused from the mucosal to the serosal side and entered into the lumen of everted intestine (absorption compartment). The samples were collected for a total period of twelve hours. The absorption compartment was sampled with replacement (KrebsRinger solution) at $0.5,1,2,3,4,5,6,7,8,9,10,11$ and $12 \mathrm{~h}$, and was determined spectrophotometrically. The whole experiment was repeated in triplicate $(n=3)$ using fresh dissolution medium as well as fresh intestinal segment each time. ${ }^{27}$

\section{RESULTS AND DISCUSSION}

Amlodipine, a sparingly soluble calcium channel receptor blocker was formulated as a solid dispersion with a sugar (Sorbitol) by the melt granulation technique. Losartan, a selective, competitive angiotensin II receptor type $1\left(\mathrm{AT}_{1}\right)$ antagonist was mixed with Avicel PH 101 and PVP K30 as binders and was formulated into mini tablets by direct compression technique.

Characterization and evaluation of Amlodipine granule and Losartan tablets were carried out along with drug release studies of assembled capsules. The effect of various parameters such as type and weight of swellable polymer used in erodible tablet and lag time determination were carried out. Formalin treated water insoluble capsule bodies were prepared and used to hold Amlodipine granules, erodible tablet and losartan core tablet.

\section{Compatibility studies}

The FT-IR spectra obtained were shown in Figure 1-6. The characteristic peaks of Amlodipine and Losartan were obtained in the spectra of pure drug were also observed at the same wavelength region in the spectra of physical mixtures of drug with Sorbitol, Crosscarmellose sodium, MCC and PVP. Pure AMLO showed IR absorption bands at $3160.50 \mathrm{~cm}^{-1}$ for the stretching vibration of $\mathrm{N}-\mathrm{H}$ bond in the dihydropyridine ring; $1432.00 \mathrm{~cm}^{-1}$ for the ethyl ester; $1383.40 \mathrm{~cm}^{-1}$ for sulphonic acid salts and $1113.40 \mathrm{~cm}^{-1}$ for the aliphatic esters. These characteristic IR absorption bands of AMLO were all retained in the granules. These results indicate that there was no interaction between the drug and granule excipients. The characteristic absorption peaks of Losartan potassium appeared at 3038.22,3399.52,1 130.98,1642.23,1356.36,15 71.12 and 2926.99 denoting stretching vibration of $\mathrm{C}-\mathrm{H}-\mathrm{N}-\mathrm{H}-\mathrm{O}-\mathrm{H}, \mathrm{C}=\mathrm{N}, \mathrm{C}-\mathrm{N}, \mathrm{N}=\mathrm{N}$

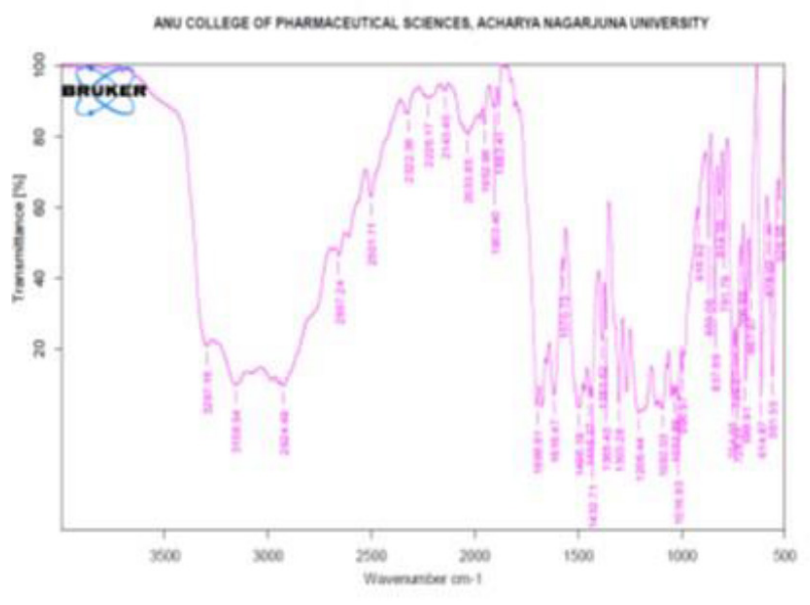

Figure 1: FT-IR Spectra of Amlodipine. 


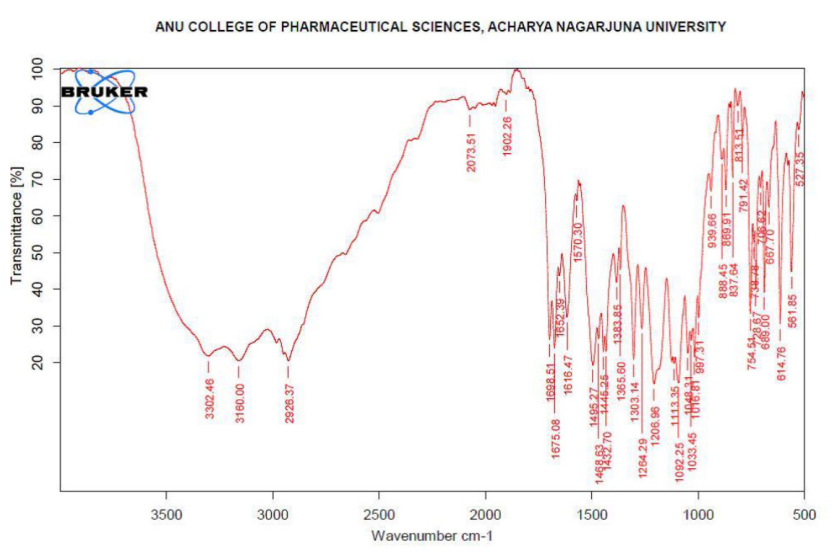

Figure 2: FT- IR spectra of Amlodipine+ Sorbital.

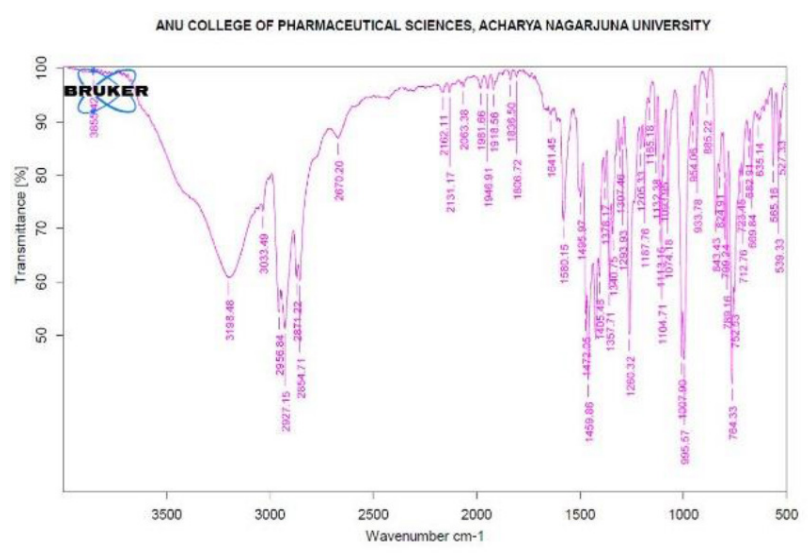

Figure 3: FT-IR spectra of Losartan.

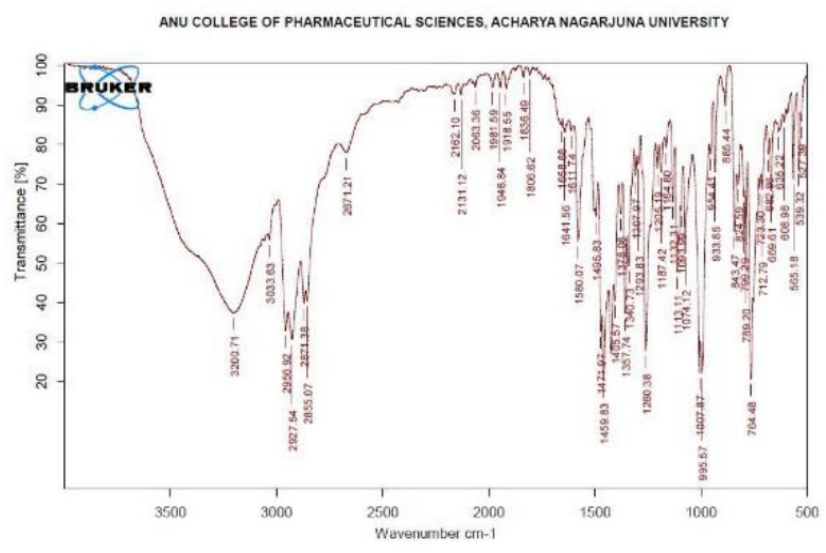

Figure 4: FT-IR spectra of Losartan+ CCS.

and aromatic ring respectively. Form the figures it was observed that same peaks were also reported in all drug and polymer mixture. There was no change or shifting of characteristic peaks suggested that there was no significant drug polymer interaction which indicates the stable nature of the drug in all formulations. These

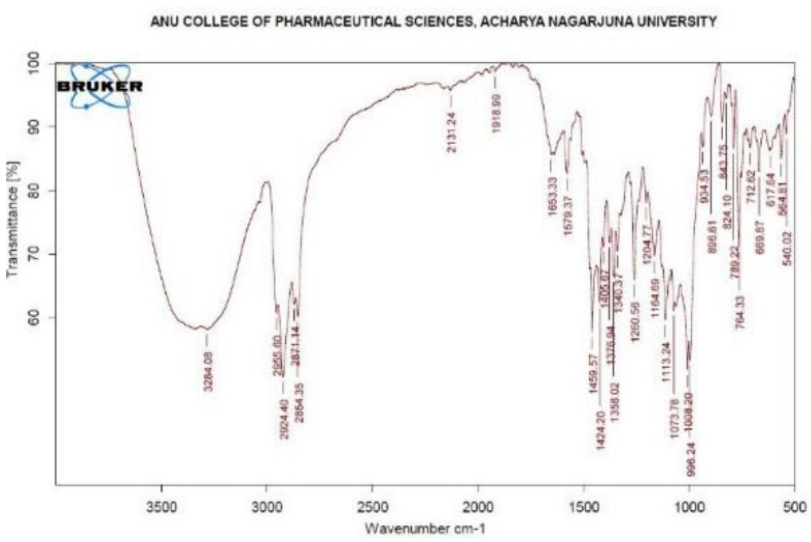

Figure 5: FT-IR Losartan Potassium+ MCC.

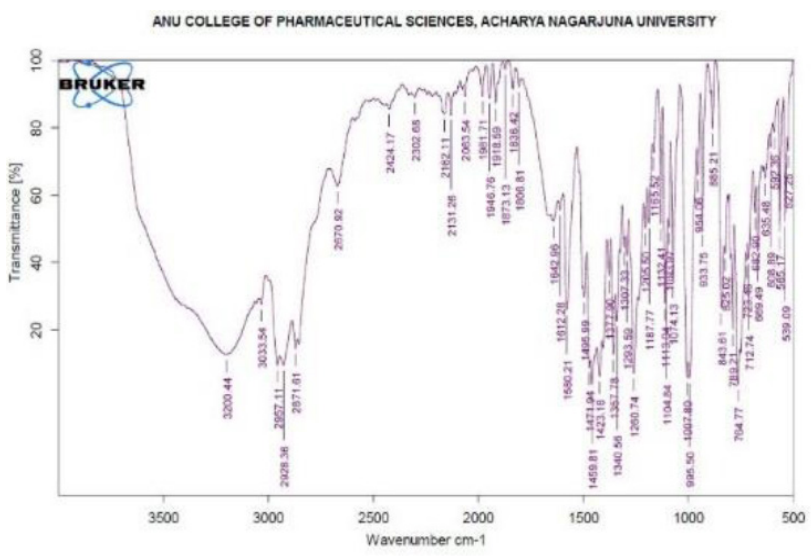

Figure 6: FT-IR spectra of Losartan Potassium+ PVP.

results indicated that Amlodipine and Losartan were compatible with the selected polymers.

\section{Evaluation of Amlodipine-Sorbitol granules Micromeritic properties}

The formulations showed bulk density values within the range of $0.480 \pm 0.32$ to $0.495 \pm 0.51$ and tapped density values of $0.563 \pm 0.23$ to $0.579 \pm 0.40$ respectively. The formulation shows the compressibility index values within the range of 22.29 to 25.60 respectively. From these results it shows good flow character. The results of hausner's ratio of all formulations were between $1.147 \pm 0.12$ to $1.160 \pm 0.24$. The formulations shows angle of repose values within the range of $23.3 \pm 0.30$ to $24.8 \pm 0.42$ respectively and the values shown in Table 4 . From these results it is concluded that it has shown good flow behaviour of blend. Density differences between the formulations were negligible indicating that the prepared granules were non-aggregated and spherical in nature. 


Table 3: In- vitro Dissolution Studies for Amlodipine-
Sorbitol Granules.
\begin{tabular}{|c|c|c|c|c|c|c|}
\hline S. No & Formulation & \multicolumn{5}{|c|}{$\%$ Cummulative Drug Release } \\
\cline { 3 - 7 } & & $\mathbf{0 . 5 h}$ & $\mathbf{1 h}$ & $\mathbf{1 . 5 h}$ & $\mathbf{2 h}$ & $\mathbf{2 . 5 h}$ \\
\hline 1 & G1 (1:1) & 74.26 & 75.59 & 76.06 & 78.37 & 78.84 \\
\hline 2 & G2 (1:0.5) & 82.99 & 85.19 & 85.74 & 86.83 & 87.38 \\
\hline 3 & G3 (1:0.25) & 91.92 & 92.12 & 93.98 & 98.51 & 98.93 \\
\hline
\end{tabular}

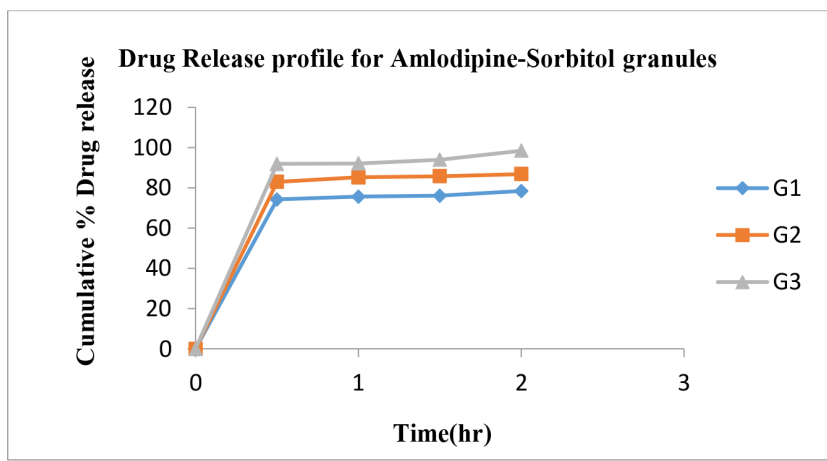

Figure 7: Drug Release Profile for Amlodipine-Sorbitol granules.

\section{Drug content}

The formulations showed the percentage of Amlodipine was ranging from 96.75 to $99.02 \%$ respectively in all formulations. This reveals that the drug is uniformly disperses in the formulations and confirms the homogenous mixing of the drug and polymer, indicating that the method used to prepare the formulations is suitable and reproducible in nature.

\section{In vitro dissolution studies}

The drug release studies for all the 3 batches of AMLOsorbitol granule formulations were carried out in $\mathrm{pH}$ 1.2 $\mathrm{HCl}$ buffer which was used for the study to mimic gastric environment. The first pulsed dose drug is contained in a soluble gelatin cap to provide immediate release after dissolving of the soluble cap. The formulations G1 showed \% drug release of range 74.26 $-78.84 \%$, G2 between $82.99-87.38 \%$, G3 in the range of 91.92 to $98.93 \%$ at $2.5 \mathrm{~h}$ and the in-vitro dissolution data was shown in Table 3 and Drug release profile was shown in Figure 7. This indicates that the amount of drug release increases with an decrease in the amount of sorbitol. The formulation G3 showed a maximum of $98.93 \%$ of drug release, hence was selected as the optimized formulation in the pulsatile capsules as the immediate release dose.

\section{Evaluation of Losartan core tablets Evaluation of micromeritic properties (Pre compression parameters)}

The formulations showed bulk density values within the range of $0.470 \pm 0.32$ to $0.509 \pm 0.23$ and tapped density values of $0.573 \pm 0.23$ to $0.599 \pm 0.26$ respectively. From these results it is concluded that it is within the acceptable limits. The formulation shows the compressibility index values within the range of 23.29 to 30.12 respectively. From these results it shows good flow character. The results of hausner's ratio of all formulations were between $1.165 \pm 0.12$ to $1.198 \pm 0.14$. From these results it shows good flow behaviour of blend. The formulations shows angle of repose values within the range of $23.3 \pm 0.30$ to $26.9 \pm 0.32$ respectively. From these results it is concluded that it has shown good flow behaviour of blend and the values shown in Table 4.

\section{Evaluation of Post compression parameters}

Hardness which is indicative of crushing strength of tablets of all formulations was within the range of 2.31 to $2.42 \mathrm{~kg} / \mathrm{cm}^{2}$. The formulation shows the friability values within the range of 0.410 to $0.510 \%$ respectively. The friability of all formulated tablets was within the limits which reveal good adhesion of tablets ingredients. The weight variation values of the tablets (F1-F6) ranged from $2.53 \%$ to $4.50 \%$ and disintegration time values within the range of 5 to $15 \mathrm{~min}$.

\section{Drug content}

Tablets displayed drug content in conformity to the pharmacopoeial limit and was ranging from 98.35 to $99.06 \%$ respectively in all formulations. This reveals that the drug is uniformly disperses in the formulations and confirms the homogenous mixing of the drug and polymer.

\section{In vitro drug release studies of Losartan core tablets}

The drug release studies for all the 4 batches of Losartan core tablet formulations were carried out in deareated water. The influence of Avicel PH101 and Crosscarmellose sodium commonly used in different ratio, on the tablet properties was investigated. In-vitro drug release profiles explicated a percentage cumulative drug release (CDR) of 67.81 to $96.15 \%, 53.88$ to $98.47 \%, 55.64$ to $91.95 \%, 66.42$ to $99.40 \%$ from formulation C1, C2, C3 and $\mathrm{C} 4$ respectively within $2.5 \mathrm{~h}$ and shown in Figure 8. $\mathrm{C} 4$ with highest concentration of Crosscarmellose was selected for fabrication of immediate release and the values shown in Table 6 . 


\section{Table 4: Pre-compression parameters of Amlodipine Granules (G1, G2, G3) and Losartan core tablets (C1, C2,} C3, C4) and Erodible Tablets (XGE1, XGE2, XGE3, XGE4, GGE1, GGE2, GGE3, GGE4).

\begin{tabular}{|c|c|c|c|c|c|}
\hline Formulation & $\begin{array}{c}\text { Angle of Repose } \\
(\mathbf{(})\end{array}$ & Bulk Density (g/ml) & $\begin{array}{c}\text { Tapped Density } \\
(\mathbf{g} / \mathbf{m l})\end{array}$ & $\begin{array}{c}\text { Compressibility } \\
\text { Index }(\mathbf{\%})\end{array}$ & Hausner Ratio \\
\hline G1 & $23.3 \pm 0.30$ & $0.480 \pm 0.32$ & $0.563 \pm 0.23$ & $22.29 \pm 0.87$ & $1.147 \pm 0.12$ \\
\hline G2 & $24.2 \pm 0.27$ & $0.489 \pm 0.49$ & $0.570 \pm 0.33$ & $23.59 \pm 0.76$ & $1.153 \pm 0.22$ \\
\hline G3 & $24.8 \pm 0.42$ & $0.495 \pm 0.51$ & $0.579 \pm 0.40$ & $25.60 \pm 0.87$ & $1.160 \pm 0.25$ \\
\hline C1 & $24.3 \pm 0.30$ & $0.470 \pm 0.32$ & $0.573 \pm 0.23$ & $23.29 \pm 0.11$ & $1.157 \pm 0.12$ \\
\hline C2 & $24.5 \pm 0.27$ & $0.481 \pm 0.49$ & $0.580 \pm 0.33$ & $24.59 \pm 0.62$ & $1.630 \pm 0.22$ \\
\hline C3 & $25.8 \pm 0.42$ & $0.493 \pm 0.51$ & $0.589 \pm 0.40$ & $27.60 \pm 0.48$ & $1.170 \pm 0.25$ \\
\hline C4 & $26.9 \pm 0.32$ & $0.509 \pm 0.23$ & $0.599 \pm 0.26$ & $30.12 \pm 0.25$ & $1.179 \pm 0.14$ \\
\hline XGE1 & $24.6 \pm 1.30$ & $0.470 \pm 0.32$ & $0.563 \pm 0.23$ & $12.29 \pm 0.32$ & $1.127 \pm 0.12$ \\
\hline XGE2 & $24.58 \pm 0.22$ & $0.481 \pm 0.20$ & $0.569 \pm 0.33$ & $13.89 \pm 0.43$ & $1.182 \pm 0.19$ \\
\hline XGE3 & $25.89 \pm 0.19$ & $0.499 \pm 0.41$ & $0.570 \pm 0.29$ & $15.62 \pm 0.36$ & $1.243 \pm 0.15$ \\
\hline XGE4 & $26.9 \pm 1.32$ & $0.509 \pm 0.23$ & $0.579 \pm 0.26$ & $17.56 \pm 0.12$ & $1.279 \pm 0.14$ \\
\hline GGE1 & $24.16 \pm 1.30$ & $0.450 \pm 0.22$ & $0.569 \pm 0.23$ & $12.49 \pm 1.32$ & $1.117 \pm 0.12$ \\
\hline GGE2 & $24.98 \pm 1.22$ & $0.471 \pm 0.20$ & $0.573 \pm 0.33$ & $13.69 \pm 1.43$ & $1.157 \pm 0.19$ \\
\hline GGE3 & $26.89 \pm 1.19$ & $0.489 \pm 0.31$ & $0.580 \pm 0.29$ & $15.22 \pm 1.36$ & $1.223 \pm 0.15$ \\
\hline GGE4 & $27.9 \pm 1.32$ & $0.500 \pm 0.23$ & $0.589 \pm 0.26$ & $17.66 \pm 1.12$ & $1.259 \pm 0.14$ \\
\hline
\end{tabular}

\begin{tabular}{|c|c|c|c|c|c|}
\multicolumn{6}{|c|}{ Table 5: Post Compression Parameters of Losartan core tablets (C1, C2, C3, C4) and Erodible Tablets (XGE1, } \\
XGE2, XGE3, XGE4, GGE1, GGE2, GGE3, GGE4). \\
\hline Formulation & $\begin{array}{c}\text { Weight Variation } \\
(\%)\end{array}$ & $\begin{array}{c}\text { Hardness } \\
(\text { Kg/Cm })\end{array}$ & Friability (\%) & $\begin{array}{c}\text { Disintegration } \\
\text { Time(min) }\end{array}$ & $\%$ Drug Content \\
\hline C1 & 2.53 & $2.35 \pm 0.52$ & $0.755 \pm 0.08$ & $15 \pm 0.60$ & $98.35 \pm 0.26$ \\
\hline C2 & 2.96 & $2.31 \pm 0.98$ & $0.410 \pm 0.56$ & $10 \pm 0.90$ & $98.98 \pm 0.29$ \\
\hline C3 & 3.89 & $2.39 \pm 0.62$ & $0.451 \pm 0.99$ & $9 \pm 0.56$ & $98.75 \pm 0.35$ \\
\hline C4 & 4.50 & $2.42 \pm 0.54$ & $0.510 \pm 0.75$ & $11 \pm 0.85$ & $99.06 \pm 0.44$ \\
\hline XGE1 & 3.53 & $3.5 \pm 0.28$ & $0.624 \pm 0.06$ & $80 \pm 0.85$ & - \\
\hline XGE2 & 3.72 & $3.2 \pm 0.52$ & $0.606 \pm 0.03$ & $90 \pm 0.71$ & - \\
\hline XGE3 & 4.33 & $3.9 \pm 0.85$ & $0.721 \pm 0.09$ & $110 \pm 0.55$ & - \\
\hline XGE4 & 4.60 & $4.5 \pm 0.22$ & $0.549 \pm 0.04$ & $120 \pm 0.51$ & - \\
\hline GGE1 & 3.58 & $3.21 \pm 0.33$ & $0.614 \pm 0.06$ & $75 \pm 0.92$ & - \\
\hline GGE2 & 3.70 & $3.32 \pm 0.21$ & $0.616 \pm 0.03$ & $80 \pm 0.75$ & - \\
\hline GGE3 & 4.39 & $3.44 \pm 0.19$ & $0.731 \pm 0.09$ & $85 \pm 0.51$ & - \\
\hline GGE4 & 4.65 & $3.51 \pm 0.29$ & $0.559 \pm 0.04$ & $95 \pm 0.62$ & - \\
\hline
\end{tabular}

\begin{tabular}{|c|c|c|c|c|c|c|c|c|c|c|c|}
\hline \multirow[t]{2}{*}{ S. No } & \multirow[t]{2}{*}{ Formulation } & \multicolumn{10}{|c|}{$\%$ Cummulative Drug Release } \\
\hline & & $0.5 \mathrm{hr}$ & $1 \mathrm{hr}$ & $1.5 \mathrm{hr}$ & $2 \mathrm{hr}$ & $2.5 \mathrm{hr}$ & $3 \mathrm{hr}$ & $3.5 \mathrm{hr}$ & $4 \mathrm{hr}$ & $4.5 \mathrm{hr}$ & $5 \mathrm{hr}$ \\
\hline 1 & $\mathrm{C} 1$ & 67.81 & 75.25 & 86.86 & 96.15 & 94.76 & 91.50 & 89.65 & 87.32 & 86.86 & 85.93 \\
\hline 2 & $\mathrm{C} 2$ & 53.88 & 85.0 & 94.76 & 97.54 & 98.47 & 84.54 & 82.68 & 80.36 & 78.96 & 75.25 \\
\hline 3 & C3 & 55.64 & 77.84 & 91.30 & 91.95 & 90.74 & 90.08 & 90.08 & 89.62 & 89.43 & 88.16 \\
\hline 4 & $\mathrm{C} 4$ & 66.42 & 72.46 & 91.04 & 97.08 & 99.4 & 92.9 & 85.47 & 83.61 & 79.89 & 76.64 \\
\hline
\end{tabular}




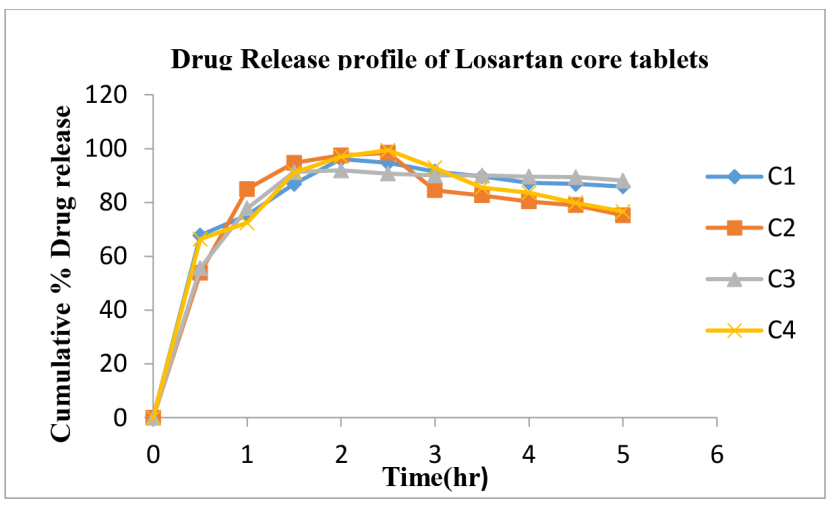

Figure 8: Drug Release profile of Losartan core tablets.

\section{Evaluation of Erodible tablets}

Evaluation of micromeritic properties (Pre compression parameters)

These properties include Bulk density, Tapped density, Compressibility index, Hausner ratio and Angle of repose. The formulations showed bulk density values within the range of $0.470 \pm 0.32$ to $0.509 \pm 0.23$ and tapped density values of $0.563 \pm 0.23$ to $0.579 \pm 0.26$ respectively. From these results it is concluded that it is within the acceptable limits. The formulation shows the compressibility index values within the range of 12.29 \pm 1.32 to $17.56 \pm 1.12$ respectively. From these results it shows good flow character. The results of hausner's ratio of all formulations were between $1.127 \pm 0.12$ to $1.279 \pm 0.14$. From these results it shows good flow behaviour of blend. The formulations shows angle of repose values within the range of $24.06 \pm 1.30$ to 26.9 \pm 1.32 respectively. From these results it is concluded that it has shown good flow behaviour of blend.

\section{Evaluation of Post compression parameters}

Erodible tablets were also evaluated for weight variation, hardness and friability (Table 5). The weight variation values within the range of $3.53 \%$ to $4.60 \%$ for $\mathrm{XG}$ tablets and $3.82 \%$ to $4.50 \%$ for GG tablets respectively and the hardness varied 4.31 to $4.42 \mathrm{~kg} / \mathrm{cm}^{2}$ for XG tablets and 3.21 to $3.51 \mathrm{~kg} / \mathrm{cm}^{2}$ for GG tablets. Grossly, as the concentration of guar gum increased, the hardness of tablets progressively increased. The friability was also within the USP limits of $<1 \%$. The formulation shows the disintegration time values within the range of 15 to 25 min.

\section{Water uptake studies}

Water uptake studies on the erodible tablets showed a linear increase in weight of the tablets. The top hydrophilic layer in the formulation is designed to absorb water and swell when it gets in contact with liquid, after swelling a gel layer is formed around the tablet which acts as a barrier that prevents the liquid from reaching the core surface. The water uptake increased linearly as the amount of xanthum gum and guar gum increased. XG showed relatively more water uptake capacity and more viscosity than GG. The percentage water content of XG tablets increased with time. The $\%$ water uptake of XG tablets was found to be 94.50 to 94.46 and GG tablets was found to be 82.27 to 87.60 .

\section{Evaluation of Pulsatile capsule}

Pulsatile capsules containing Amlodipine-Sorbitol granules (G3) and a second pulse of Losartan core tablet (C4) in the insoluble capsule body sandwiched between erodible polymer tablets and swellable polymer layer were developed. When the capsule reaches the stomach fluids the cap dissolves and amlodipine granules are released. The swellable polymer layer at the base of the capsule body along with the erodible tablet swells up on absorbing body fluids and after a long period of 6-8h, the plug is pushed out releasing the Losartan tablet. The weight variation of pulsatile capsules was found to be within the official limits.

\section{Lag time determination}

With the $100 \mathrm{mg}$ erodible tablets, Losartan release started very fast, lag time was at $5 \pm 1 \mathrm{~h}$. In all the cases the erodible tablet remained at the mouth of the capsule and could not be expelled so $100 \mathrm{mg}$ erodible tablets proved ineffective to allow proper drug release after a desired lag time. Then the swelling polymer in the capsule was increased to $150 \mathrm{mg}$ then complete drug release was observed at the end of $12^{\text {th }}$ hour with a lag time of $6 \mathrm{~h}$. Subsequent trials were carried out using $150 \mathrm{mg}$ erodible tablet of GG and XG as swelling polymer. Lag time for drug release was in the range of 6-7 $\mathrm{h}$ after which the plug was pushed out and rapid drug release was seen. On exposure to the dissolution fluids, the guar gum gets hydrated and forms a viscous colloidal dispersion that slows down further seeping-in of dissolution fluids which retards drug release. The retarding influence of guar gum may be reasoned for its hydrophilic and swelling ability in water. On coming in contact with biological fluids, guar gum swells up and the drug release takes place by diffusion. High degree of swelling to form thick gel layer and extensive polymerization in contact with water slows down erosion rate. The mechanical erosion of the swollen guar gum layer would follow this. Unless the swollen guar gum layer erodes, further hydration and swelling of the guar gum does not take place. On reaching the colonic environment, the colonic bacterial enzymes would act upon the 
swollen guar gum layer and releases the drug contained in the swollen guar gum layer and these findings indicate that the presence of lactose, particularly in high quantities, affects considerably the character of polymer. As mentioned earlier, this is probably because of the large disruption of polymer mass, followed by rapid erosiondissolution, which as a result increases drug release from the system

\section{Solubility study for the treated capsules}

When the capsules were subjected to solubility studies in $0.1 \mathrm{~N} \mathrm{HCl}$ for $24 \mathrm{~h}$, the observation was found that the normal capsules both cap and body dissolved within fifteen minutes and another formaldehyde treated capsules, only the cap dissolved within 15 minutes remaining body of capsule intact for about $24 \mathrm{~h}$. Present work concludes that $8 \mathrm{~h}$ formaldehyde treatment is sufficient to sustain the release for $12 \mathrm{~h}$ and found that the capsule has maintained the physical stability during the dissolution process.

\section{Quantitative test for free formaldehyde}

The formaldehyde capsules were tested for the presence of free formaldehyde. The sample solution was not more intensely coloured than the standard solution inferring that less than $20 \mu \mathrm{g}$ free formaldehyde is present in 25 capsule.

\section{In vitro drug release, kinetics and optimization of pulsatile capsule}

Drug release studies were necessary to ensure that the erodible tablets could effectively seal the mouth of the capsule body. Thus dissolution studies of pulsatile capsules were carried out in $0.1 \mathrm{~N} \mathrm{HCl}$ for $3 \mathrm{~h}$, followed by distilled water for next $9 \mathrm{~h}$. Amlodipine-Sorbitol granules of G3 ratio, Losartan core tablet of C4 formulation and Erodible tablet of Guar gum with E4 formulation were selected for in vitro drug release of pulsatile capsule. A comparison was done between formaldehyde treated capsules and untreated capsule and drug release kinetics were also compared and the data was shown in Table 7. Where amlodipine showed $99.29 \%$ drug release at the end of $3^{\text {rd }}$ hour in treated capsule and $99.70 \%$ drug release in untreated capsule and shown in Figure 9 and 10 Whereas Losartan potassium showed $92.93 \%$ drug release at the end of $12^{\text {th }}$ hour in treated capsule and $96.15 \%$ drug release at the end of $4^{\text {th }}$ hour only in untreated capsule. The correlation coefficient values for dissolution kinetics data was observed. These values clearly indicated that the in-vitro release of formulation was best fitted to Zero- order kinetics and the mechanism of drug release was governed by Peppas - Korsmeyer model. The exponential coefficient (n) values were
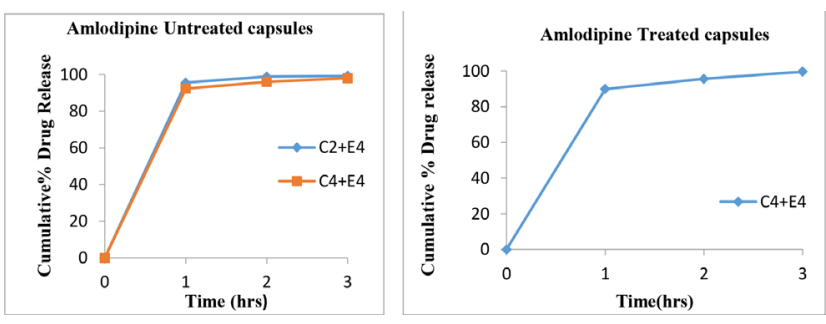

Figure 9: Release Profile plot for Amlodipine in Pulsatile Capsule of Untreated caps and Treated caps.
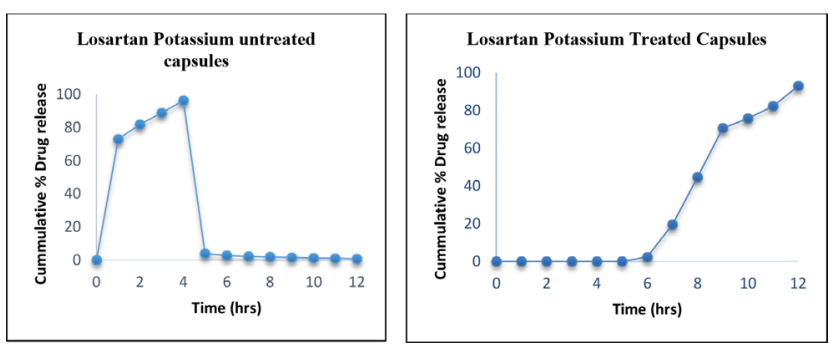

Figure 10: Release Profile plot for Losartan Potassium in Pulsatile Capsule of Untreated caps and Treated caps.

found to be in between 0.8500 to 0.8956 indicating that the drug release followed non-fickian diffusion mechanism.

\section{In vitro comparison of pulsatile capsule with Marketed formulation}

Marketed formulation of combination of Amlodipine and Losartan was compared with the prepared pulsatile capsule. Peak concentration was attained at $3 \mathrm{~h}$ only for marketed formulation.

\section{Continuous dissolution-absorption studies (Ex-vivo studies)}

Ex-vivo studies were performed using sheep intestine. The values of percent of drug dissolved and percent of drug absorbed showed that there was increase in percent of drug dissolved percent of drug absorbed with increase in time. The absorption of dissolved drug was more in stomach at $\mathrm{pH} 1.2$ than in intestine at $\mathrm{pH}$ 6.8. Amlodipine exhibits $\mathrm{T}_{\max }$ of 2.5-3 $\mathrm{h}$ and Losartan exhibits 7-9h. The optimized formulation which consists of G3, C4 and E4 was carried out for dissolution initially in gastric media $(0.1 \mathrm{~N} \mathrm{HCl})$ for $3 \mathrm{~h}$ followed by intestinal media (distilled water) for $12 \mathrm{~h}$. Amlodipine granules were released immediately after capsule cap dissolution while losartan was released after lag time of 6-7 h. Thus though the designed pulsatile formulation the two drugs should reach peak plasma concentrations at almost the same time. In the case of marketed formulation, both the drugs were released immediately in gastric media $(0.1 \mathrm{~N} \mathrm{HCl})$ which was available for absorption was shown in Figure 11. The optimized formulation showed 


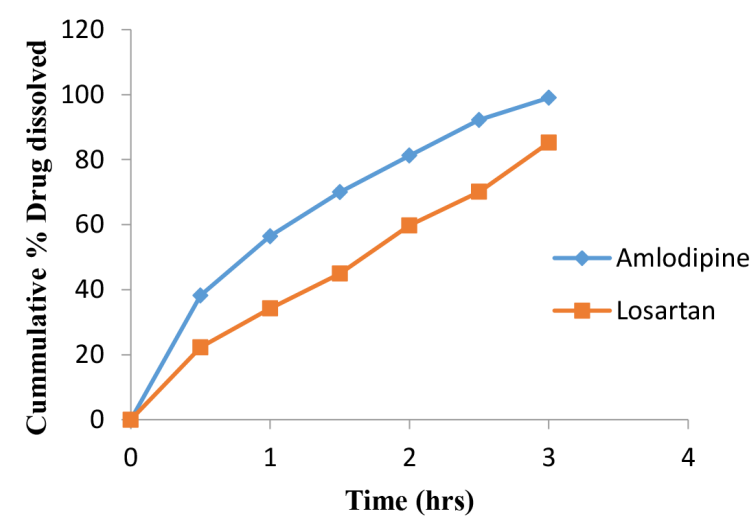

Figure 11: Release Profile plot for Amlodipine and Losartan Potassium in Marketed Formulation.

Table 7: Percent Drug release profile for Treated and Untreated Capsule.

\begin{tabular}{|c|c|c|c|c|c|}
\hline \multirow{2}{*}{$\begin{array}{c}\text { S. } \\
\text { No. }\end{array}$} & $\begin{array}{c}\text { Time } \\
\text { (hours) }\end{array}$ & \multicolumn{2}{c|}{$\begin{array}{c}\text { \% Drug release for } \\
\text { Amlodipine Besylate }\end{array}$} & \multicolumn{2}{c|}{$\begin{array}{c}\text { \%osurtan release for } \\
\text { Lotassium }\end{array}$} \\
\cline { 3 - 6 } & & $\begin{array}{c}\text { Treated } \\
\text { capsule }\end{array}$ & $\begin{array}{c}\text { Untreated } \\
\text { capsule }\end{array}$ & $\begin{array}{c}\text { Treated } \\
\text { capsule }\end{array}$ & $\begin{array}{c}\text { Untreated } \\
\text { capsule }\end{array}$ \\
\hline 1 & 1 & 95.61 & 89.89 & 0 & 72.92 \\
\hline 2 & 2 & 98.88 & 95.61 & 0 & 81.75 \\
\hline 3 & 3 & 99.29 & 99.70 & 0 & 88.72 \\
\hline 4 & 4 & 1.60 & 0.40 & 0 & 96.15 \\
\hline 5 & 5 & 1.15 & 0.32 & 0 & 3.85 \\
\hline 6 & 6 & 1.01 & 0.29 & 2.30 & 2.73 \\
\hline 7 & 7 & 0.94 & 0.25 & 19.54 & 2.15 \\
\hline 8 & 8 & 0.85 & 0.21 & 44.68 & 1.84 \\
\hline 9 & 9 & 0.70 & 0.17 & 70.60 & 1.49 \\
\hline 10 & 10 & 0.49 & 0.11 & 75.71 & 1.17 \\
\hline 11 & 11 & 0.36 & 0.06 & 82.21 & 0.94 \\
\hline 12 & 12 & 0.21 & 0.03 & 92.93 & 0.73 \\
\hline
\end{tabular}

a better correlation between the percent of drug dissolved and percent of drug absorbed which indicated better absorption and permeation of the dissolved drug.

\section{In vitro and ex vivo comparison studies for pulsatile capsules}

In vitro studies of prepared pulsatile capsules were compared with the ex vivo studies. Drug release for Amlodipine in Pulsatile capsule was found to be $99.29 \%$ and $70.25 \%$ in intestine at the end of $3^{\text {rd }}$ hour. Losartan was found to be $89.53 \%$ in the capsule and $61.15 \%$ in intestine at the end of $12^{\text {th }}$ hour and the values were shown in Table 8 .
Table 8: Comparison of in vitro and ex vivo Dissolution Studies for Pulsatile capsule.

\begin{tabular}{|c|c|c|c|c|c|}
\hline $\begin{array}{c}\text { S. } \\
\text { No. }\end{array}$ & $\begin{array}{c}\text { Time } \\
\text { (hours) }\end{array}$ & \multicolumn{2}{|c|}{$\begin{array}{c}\text { \% Drug release for } \\
\text { Amlodipine Besylate }\end{array}$} & \multicolumn{2}{c|}{$\begin{array}{c}\text { \% Drug release for } \\
\text { Losartan Potassium }\end{array}$} \\
\cline { 3 - 6 } & & $\begin{array}{c}\text { Treated } \\
\text { capsule }\end{array}$ & Intestine & $\begin{array}{c}\text { Treated } \\
\text { capsule }\end{array}$ & Intestine \\
\hline 1 & 1 & 95.61 & 41.97 & 17.18 & 4.168 \\
\hline 2 & 2 & 98.88 & 49.96 & 22.29 & 2.094 \\
\hline 3 & 3 & 99.29 & 70.25 & 27.87 & 6.020 \\
\hline 4 & 4 & 7.29 & 31.25 & 33.90 & 6.946 \\
\hline 5 & 5 & 7.01 & 29.89 & 42.27 & 8.798 \\
\hline 6 & 6 & 6.89 & 22.56 & 49.23 & 10.18 \\
\hline 7 & 7 & 6.03 & 17.48 & 58.99 & 12.03 \\
\hline 8 & 8 & 5.59 & 12.27 & 64.56 & 16.19 \\
\hline 9 & 9 & 5.01 & 8.29 & 70.60 & 19.89 \\
\hline 10 & 10 & 4.46 & 5.74 & 75.71 & 23.12 \\
\hline 11 & 11 & 3.23 & 3.33 & 82.21 & 44.68 \\
\hline 12 & 12 & 2.09 & 1.29 & 85.93 & 61.15 \\
\hline
\end{tabular}

\section{Stability}

The stability analysis revealed no change in physical appearance of the dosage form. Drug content at 0,15 , 30,60 and 90 day was documented to be $98.62 \pm 0.16 \%$, $98.01 \pm 0.33 \%, 98.67 \pm 0.13 \%, 97.23 \pm 0.11 \%, 97.11 \pm$ $0.24 \%$ and $96.43 \pm 0.33 \%$ respectively. The shelf life of dosage form was documented to be 18 months.

\section{Future Scope}

In -vivo study can be done. Pharmacokinetic and toxicity study can be done. Stability studies-long term has to be done.

\section{CONCLUSION}

Promising Pulsatile release system for amlodipine besylate and Losartan Potassium with appropriate amounts of excipients is successfully developed on the lines of novel drug delivery systems. They provided a desirable lag time followed by rapid and complete drug release to meet the challenges of chronotherapeutics of hypertension.

\section{ACKNOWLEDGEMENT}

The authors are thankful to University College of Pharmaceutical Sciences, Acharya Nagarjuna University and Hetero Laboratories Ltd. Hyderabad for providing APIs Losartan Potassium and Amlodipine Besylate as gift sample.

\section{CONFLICT OF INTEREST}

The authors declare no conflict of interest. 


\section{ABBREVIATIONS}

API: Active Pharmaceutical Ingredient; FTIR: Fourier Transmission Infrared; AMLO: Amlodipine besylate; PVP-K30: Polyvinylpyrrolidone-K30.

\section{SUMMARY}

From the above work it can be concluded that the drug polymer compatibility studies were found to be satisfactory. Preformulation studies were performed for pure drug and granules. The flow properties were found to be good. Physical compatibility study showed that the drug and excipient were physically compatible with each other. Chemical compatibility study using FTIR spectroscopy revealed no interaction between $\varpi$ the drug and excipients. The capsule body was made insoluble by formaldehyde treatment and were subjected to various physical and chemical test such as solubility studies and qualitative for free formaldehyde. The in vitro release studies were performed for all the formulations. Pulsincap formulated with Amlodipine-Sorbitol granules of G3 formulation, Losartan core tablet of $\mathrm{C} 4$ formulation and Erodible tablet of Guar gum with E4 formulation showed highest drug release over the period of $12 \mathrm{~h}$ and release was found to be followed Higuchi model kinetics. Therefore it was chosen as the optimized formulation for pulsincap.

\section{REFERENCES}

1. Mazuski C, Herzog ED. Circadian rhythms: to sync or not to sync. Curr Biol. 2015;25(8):R337-339.

2. Takeda N, Maemura K. The role of clock genes and circadian rhythm in the development of Cardiovascular diseases. Cell Mol Life Sci. 2015;72(17):3225-34.

3. Hong YJ, Jeong MH, Cho KH, Kim MC, Lee KJ, Kim KH. Impact of renal function on Changes of plaque characteristics in non-intervened coronary segments after rosuvastatin Treatment in patients with angina pectoris and hypertension. Int J Cardiol. 2015;187:286-7

4. Tousoulis D, Androulakis E, Kontogeorgou A, Papageorgiou N, Charakida M, Siama K. Insight to the pathophysiology of stable angina pectoris. Curr Pharm Des. 2012;19(9):1593-600.

5. Schillaci G, Battista F, Settimi L, Schillaci L, Pucci G. Antihypertensive drug treatment and Circadian blood pressure rhythm: a review of the role of chronotherapy in hypertension. Curr Pharm Des. 2015;21(6):756-72.

6. Romano S, Chacko SJ, Rangarajan V, Chung J, Farzaneh-Far A. Resistant hypertension. Am J Med. 2015;128(10):23-5

7. Desavathu M, Pathuri R, Chunduru M. Design, Development and Characterisation of Valsartan Microsponges by Quasi Emulsion Technique and the Impact of Stirring Rate on Microsponge Formation. J App Pharm Sci. 2017;7(01):193-8.

8. Cugini P. The treatability of refractory or resistant hypertension by personalized anti-hypertensive chronotherapy based on ambulatory monitoring of the arterial pressure. Recent Prog Med. 1996;87(2):51-7.
9. Cugini P. Compliance and the chronotherapy of refractory arterial hypertension. Recent Prog Med. 1997;88(10):463-9.

10. Hermida RC, Calvo C, Ayala DE, Mojon A, Rodriguez M, Chayan L. Administration time dependent effects of valsartan on ambulatory blood pressure in elderly hypertensive subjects. Chronobiol Int. 2005;22(4):755-76.

11. Shishehbori F, Mortazavia SA, Jafariazar Z, Rad RT. Formulation and in vitro evaluation of ketoprofen gastric floating matrix tablet based on gas formation. International journal of Applied Biology and Pharmaceutical Technology. 2015;6(2):85-93.

12. Wang Z, Wu H, Liao C, Zhou N, Cheng W, Wan Y. Sustained release of ketoprofen from fibrous chitosan-poly ( $\varepsilon$-caprolactone) membranes. Carbohydr Polym. 2011;84(1):624-30.

13. Rao NGR, Soumya P, Revathi K, Nayak BS. A review on pulsatile drug delivery system. Int Res J Pharm. 2013;4(3):31-44.

14. Zhang Z, Qi X, Li X, Xing J, Zhu X, Wu Z. A novel pulsatile drug delivery system based on the physiochemical reaction between acrylic copolymer and organic acid: in vitro and in vivo Evaluation. Int J Pharm. 2014;462(12):66-73.

15. Reinberg A. Clinical chronopharmacology: an experimental basis for chronotherapy. In: Reinberg A, Smolensky MH, editors. Biologic rhythms and medicine. Cellular, Metabolic, pathophysiologic and pharmacologic aspects. Heidelberg Springer. 1983;243-8.

16. Reinberg AE. Concepts of circadian chronopharmacology. In: Hrushesky WJM, Langer R, Theeuwes F. editors. Temporal control of drug delivery. Ann NY Acad Sci. 1991;618:102-15

17. Bussemer T, Dashevsky A, Bodmeier R. A pulsatile drug delivery system based on Rupturable coated hard gelatin capsules. J Control Release. 2003;93(3):331-9.

18. Efentakis M, Koligliati S, Vlachou M. Design and evaluation of a dry coated drug delivery system with an impermeable cup, swellable top layer and pulsatile release. Int J Pharm. 2006;311(1-2):147-56.

19. Gohel MC, Sumitra GM. Modulation of active pharmaceutical material release from a novel 'tablet in capsule system' containing an effervescent blend. J Controlled Release. 2002;79:157-64.

20. Mastiholimath VS, Dandagi PM, Jain SS, Gadad AP, Kulkarni AR. Time and $\mathrm{pH}$ dependent colon specific, pulsatile delivery of theophylline for nocturnal asthma. Int J Pharm. 2007;328:49-56.

21. Pharmaceutical dosage forms: Tablets. Vol. II. Edited by H. H. Lieberman, L. Lachman, and J. B. Schwartz. Marcel Dekker: New York. 1989.

22. Wells JI, Aulton ME. Pharmaceutical preformulation, in: M.E. Aulton (Ed.), Aultons Pharmaceutics-the Design and Manufacture of Medicines, $3^{\text {rd }}$ ed., Elsevier, Churchill Livingstone. 2007;337-60.

23. Gangwar G, Kumar A, Pathak K. Utilizing Guar Gum for Development of "Tabs In Cap' System of Losartan Potassium for Chronotherapeutics. International Journal of Biological Macromolecules. 2014;72:812-8.

24. Krogel I, Bodmeier R. Pulsatile drug release from an insoluble capsule body controlled by an erodible plug. Pharm Res. 1998;15(3):474-81.

25. Garg BK, Gnanarajan G, Kothiya P. Formulation and Evaluation of Pulsatile Drug Delivery System of Rosuvastatin Calcium Using Different Swelling Polymers. The Pharma Innovation. 2012;1(7):61.

26. Efentakis M, lliopoyloy A, Siamidi A. Effect of core size and excipients on the lag time and drug release from a pulsatile drug delivery system. Drug Development and Industrial Pharmacy. 2011;37(1):113-20

27. Kale VV, Kasliwal RH, Avari JG. Attempt to design continuous dissolutionabsorption System using everted intestine segment for in-vitro absorption studies of slow drug release Formulation. Dissol Tech. 2007;(5):31-6. 
PICTORIAL ABSTRACT

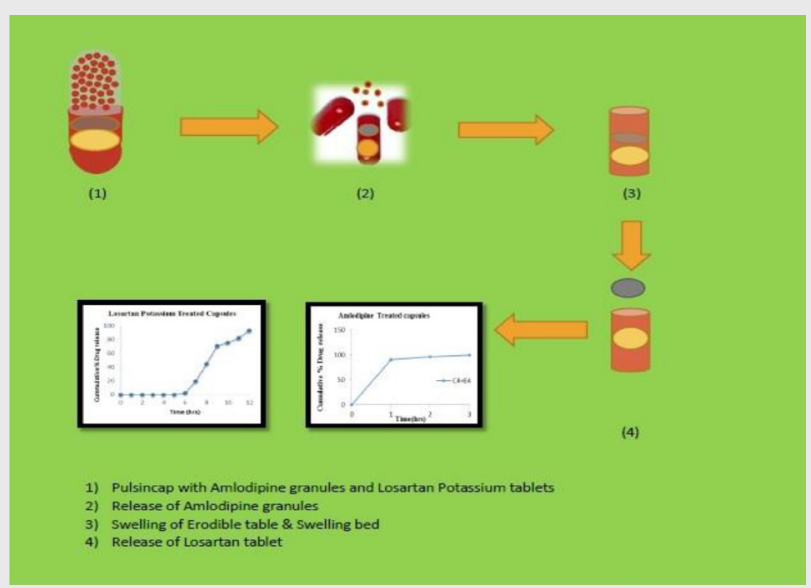

\section{SUMMARY}

To programme the release of dual anti hypertensive drugs to mimic the circardian pattern of blood pressure, a pulsatile capsule with amlodipine besylate and losartan potassium and make it pulsatile. The modified pulsincap of dual drugs has followed huguchis model kinetics and achieved time dependent and site specific delivery

\section{About Authors}

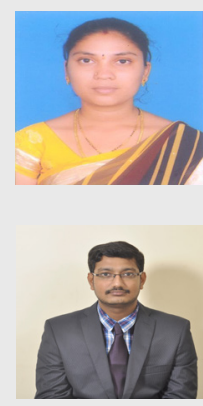

D.Madhuri: Working as Assistant Professor in Department of Pharmaceutics, University College of Pharmaceutical Sciences,Acharya Nagarjuna University. She has experience in the areas of dosage form designing and pulsative drug delivery systems.

P. Raghuveer Working as Assistant Professor in Department of Pharmaceutics, University College of Pharmaceutical Sciences, Acharya Nagarjuna University. He has experience in the areas of dosage form designing and self nano emulsifying drug delivery systems.

Cite this article: Desavathu M, Raghuveer P, Sarada P. Insertion of Dual Drugs of Hypertension in Gelatin Pockets for Chrono Pharmacotherapy and its Evaluation by in-vitro and ex-vivo Studies. Indian J of Pharmaceutical Education and Research. 2018;52(4 Suppl 2):s184-s196. 